\title{
MATRIZ DE ESPECIFICAÇÕES: suporte operacional de uma avaliação
}

SÉRGIO FRANCISCO COSTA*

\section{A PROVA COMO INSTRUMENTO DE MEDIDA}

Por que se fazem provas? Que é que uma prova pretende medir? Comecemos dizendo que uma prova, quando bem concebida, bem montada, é um instrumento de coleta e ao mesmo tempo de medida. Assim, da correta aplicação desse instrumento, resulta, em geral, um número que exprime uma relação quantitativa entre o que queremos medir e a própría escala de medida. Por seu turno, a escala de medida é uma espécie de "linguagem do instrumento".

Mas por que o educador precisa desse número? Precisa dele por várias razöes,dentre as quais: nos;

a) estabelecer comparaçōes entre as competências individuais dos alu-

b) ter uma visão geral do andamento e desenvolvimento dos alunos com relação aos objetivos gerais e específicos propostos no início de cada período escolar;

c) calibrar (ou recalibrar) a sua ação docente em função da qualidade das respostas dos alunos.

Nấo percamos de vista que

medir é atribuir números a uma grandeza.

de conformidade com um critério.

- Fundação Carlos Chagas e Universidade do Grande ABC - São Cactano do Sul 
Então, o importante é que esse critério contenha algumas características desejáveis: sólido, no sentido de não-ambíguo, simples, ou seja, pouco ou nada dependente de sofisticaçöes operacionais, e interpretável, o que significa näo deixar dúvidas sobre as relações quantitativas ou posicionais por ele sugeridas.

Essas características desejáveis consolidam-se numa escala de medida que, sendo a linguagem do instrumento, anuncia, através de um número, a quantidade que a magnitude medida tem de determinado traço.

Assim, uma prova, enquanto instrumento de medida, "pergunta" ao aluno o que e quanto ele sabe sobre determinado assunto e nh̆o há como conseguir que ela cumpra esse desiderato se, na base de sua concepçīo, nfio existirem objetivos claramente definidos.

Embora soe redundante, uma avaliaçáo é sempre maior do que a prova que the dá origem. O avaliador (professor), tendo atribuído, com base numa prova, por exemplo, certa nota a um aluno, cumpriu apenas uma parte da tarefa avaliativa; a avaliação se completa a partir do momento em que são feitas reflexões sobre alguns aspectos bem como tomadas algumas providências tendentes a produzir resultados educacionais melhores. Por exemplo, $\mathrm{e}$ seguramente sem esgotar a lista:

- o aluno não está aprendendo ou eu (professor) năo estou tendo sucesso em fazê-lo aprender?;

- o aluno está próximo ou distante da média da classe?;

- os objetivos propostos (para a unidade submetida à prova) foram efetivamente cumpridos?;

- os materiais didáticos utilizados contribuíram efetivamente para a obtençăo dos resuitados?;

- o meu discurso (de professor) leva em conta a maturidade do aluno e os seus recursos de comunicação e compreensäo?

Alem disso, essa avaliação, para ser boa, deve caracterizar-se por justiça, adequação e coerência:

- Justiça - o aluno tem o direito de ser avaliado nảo só com vistas a uma promoção senão também para situar-se relativamente ao conteúdo e ao nfvel da classe. Além disso, ele não deve ter a sensação de que há um componente paternalista no processo avaliativo segundo o qual as notas poderiam não estar relacionadas com o seu desempenho. Por isso, a comunicação do critério de correçăo deve ser anterior à aplicaçăo da prova, de modo que, ao concluf́la, o aluno possa ter uma razoável idéía da nota que irá tirar.

- Adequação - uma prova escolar é um instrumento de medida como qualquer outro. Por essa razło, sua característica fundamental deve ser a validade. Se a prova não medir o traço ou o conjunto de traços que o avaliador tem em mente medir, sua validade estará seriamente comprometida. A adequação também diz respeito à relaçäo entre o tamanho da prova c o tempo disponível para realizí-la. Submeter um aluno a um conjunto de 100 questöes de certa dificuldade em tempo insuficiente é correr o risco de estar medindo, 
além do desempenho, resistência física (ou psíquica). Ora, para medir resistência física existem instrumentos bem melhores do que uma prova escolar: corrida, levantamento de pesos, vigília etc...!

- Coerência - a coerência diz respeito a como o professor usa a avaliaçăo relativamente aos seus acordos com a classe. Em outras palavras, não deixar de cobrar, mas não cobrar além do combinado, năo cobrar aquém do combinado.

\section{TIPOS DE PROVA}

Fazendo uma supersimplificaçäo, é possível classificar as provas em dois grandes grupos: não-objetivas e objetivas.

As provas não-objetivas possuem algumas características importantes:

- fáceis de montar, difíceis de corrigir;

- possuem embutido forte elemento emocional (pessoal);

- impedem a comunicaçăo rápida dos resultados;

- sofrem fortemente a influência de fatores psicológicos da parte de quem as corrige.

As provas objetivas, por seu turno, possuem as seguintes características importantes:

- dificeis de montar, fáceis de corrigir (com base em gabaritos de correção);

- elementos emocionais embutidos praticamente inexistentes;

- favorecem a comunicaçăo rápida dos resultados;

- não sofrem a influência de fatores psicológicos da parte de quem as corrige, isto $\hat{e}$, duas pessoas distintas logram atribuir a mesma nota a uma mesma prova;

- o mesmo avaliador, ao recorrigir a mesma prova algum tempo depois, atribui-lhe a mesma nota.

\section{NÍVEIS DE CONHECIMENTO}

Existem, grosso modo, três níveis de conhecimento: reconhecimento, evocação e domínio (ou maestria). Se queremos que um aluno reconheça algo que the foi ensinado, é fundamental que the mostremos a coisa entre outras para que ele possa identificá-la. Ou cle discrimina ou não discrimina. Se queremos que ele demonstre domínio, mandamos que faça algo, estimulamo-lo a exibir comportamentos que sugiram sua maestria no assunto.A prova de múltipla escolha presta-se muito bern a medir os dois níveis de conhecimento retromencionados. A prova dissertativa (näo-objetiva), por seu tumo, é muito bon para dar ao aluno a oportunidade de demonstrar evocação; mas, como isso está estreitamente ligado à memória, a oportunidade para demonstrar o que sabe pode não ser eqüivalente à oportunidade que o professor quis dar ao aluno para que demonstrasse saber o que de fato era julgado importante! 


\section{O MAPA SUGERE O CAMINHO}

Supondo aceita a hipótese de que provas objetivas possam realmente oferecer melhor serviço à causa da avaliaçăo escolar, o foco de nossas consideraçб̌es, daqui por diante, estará centrado sobre elas.

Relembremos que uma prova, entendida como um conjunto de itens (questões), constitui uma amostra dentre as infinitas possibilidades de outras provas a que os alunos poderiam ser submetidos. Entảo, para que elas sirvam bem ao seu propósito, é preciso que os itens sejam construídos em sintonia com objetivos específicos.

Parece inegável que viajar munido de mapas torna a viagem mais segura e possivelmente mais agradável. $O$ mapa possibilita enxergar, por antecipaçăo, algumas peculiaridades geográficas bem como, se for o caso, evitar outras. Em Educação năo é diferente! Os objetivos servem de referencial para a concepçăo de um curso, para a eleição de disciplinas, para a escolha do docente ideal ou para a construçäo de provas que forneçam as evidencias necessárias a jấ mencionada avaliaçắo. Por isso, o ponto de partida para a construçã̃o de itens deve ser sempre o conjunto de objetivos de aprendizagem estabelecidos para a unidade estudada.

Os objetivos de aprendizagem "iluminam" a trajetória do educando, dando sentido às açóes a que o processo educacional o submete.

Tecnicamente, o "mapa", isto é, os objetivos de aprendizagem podem ser reunidos num quadro plano que relaciona traços de interesse (eategorias) com conteúdos. O resultado final ć uma matriz ou tabela de especifícaçōes, que informa o autor de itens do que ele deverá questionar (conteúdo), com que objetivos (traços de interesse) c quantidade ideal de itens para a mensuraçäo do cumprimento dos objetivos de aprendizagem estabelecidos.

Naturalmente, essa matriz pode variar em funçăo de diversas especificaçǒes: disciplina, grau escolar, tempo disponível (para a prova) e objetivos específicos (por exemplo, nível de dificuldade). De qualquer modo, se a prova é mais do que uma simples coleção de questốes, se o seu objetivo é coletar informações a respeito do que o aluno sabe e quanto sabe sobre determinado assunto, deve ela representar, através das questőes, uma espécie de "sonda" que capte a descjável relação entre o que elas perguntam e os objetivos que instruem cada uma delas.

\section{MODELO TRIDIMENSIONAL DA MATRIZ DE ESPECIFICAÇÕES}

A tarefa de construir em larga escala bons itens (questöes) depende do cumprimento de importantes fases, que se sucedem em ordem mais ou menos 
fixa. A primeira fase consiste em decidir que disciplina será objeto de exame (Matemática, Português, História etc.) e em que nível escolar ela se situa (por exemplo, $1^{\circ}$ grau $-3^{a}$ séric; $2^{\circ}$ grau - $1^{a}$ série etc.). Essas duas informaçőes contextualizam a matéria em alguma proposta curricular.

Tomada essa decisão, convidam-se a seguir professores experientes da disciplina escolhida e estudiosos de curricula e pede-se-lhes que, com base no material didático disponível no mercado, na sua experiência pessoal, no exame que tem sido feito das estruturas lógicas da disciplina e em suas convicções enquanto educadores, construam uma lista que arrole os conteúdos (da disciplina em causa) considerados relevantes. Essa lista, depois de exaustivamente analisada, é hierarquizada (do geral para o específico) e cada tópico é desdobrado em seus aspectos essenciais. Por exemplo, na disciplina Matemática, o tópico números pode ser desdobrado em inteiros, frações, porcentagens e decimais. Assim, tópicos definem áreas de conteúdo e desdobramentos definem conteúdos específicos.

A tarefa, a seguir, consiste em estabelecer, relativamente a cada área de conteúdo e a cada conteúdo especifico, os processos cognitivos implicados na aquisiçå̃o e no desenvolvimento do seu conhecimento. Isso, naturalmente, implica ter, na base de todas as decisões, uma taxonomia; e embora existam várias disponíveis, é sempre possível buscar uma que resulte da propria matéria sob exame, a exemplo da que emergiu em trabalho recente realizado na Fundaçăo Carlos Chagas, a proposito de uma pesquisa solicitada pelo Sistema Nacional de Avaliaçăo da Educação Básica (SAEB) realizado em 1995 em continuação de etapas anteriores (1990 e 1993). Assim, relativamente à dimensão cognitiva, ficou estabelecido trabalhar, em Matemática, com conceitos, com procedimentos e com aplicações, reunidos sob a denominação genérica de processos cognitivos. Nessa linha de raciocínio, ficam, por conta de conceitos, termos, definições, princípios; por conta de procedimentos ficam cálculos, reformulaçổes, construções, estimações, execução de algoritmos; finalmente, sob aplicações reúnem-se provas, inferências, solução de problemas expressos em linguagem natural e aplicações no mundo real*.

Cruzando-se então conteúdos com processos cognítivos, numa tabela de dupla entrada, resultam caselas que encerram ("aprisionam", enquadram) objetivos curriculares específicos. Aí, é construir itens que meçam especificamente cada objetivo curricular, com o cuidado de, na medida do possível, evitar contaminações entre caselas contíguas. Mas a construção de itens deve levar em conta mais uma varí́vel: o nível de escolaridade pressuposto na sua resoluçăo, o que é dado pelo grau e pela série curriculares.

Numa tentativa de tornar mais viś́vel a matriz de especificaçöes, procuramos compará-la a um cubo, cuja largura representasse os processos cognitivos;

- Algumas das iétias contidas nesta pógina foram inspiradas em trabalhos ainda nfo divalgados de autorin de Philip R. Fletcher. Pesquisndor Sênior da Funduçỏo Carlos Chagns. 
o comprimento, os conteúdos; e a altura, a segmentação dos conteúdos e dos processos, em ordem crescente, e em função do grau e da série. $\mathrm{Na}$ figura a seguir, o lado esquerdo do cubo abriga conceitos; o lado direito, aplicaçठ̄es; a parte central, procedimentos. Cada cubo miniaturizado, por sua vez, abriga, pelo menos teoricamente, um único objetivo curricular e a totalidade dos cubinhos representa a matriz de especificaçôes completa.

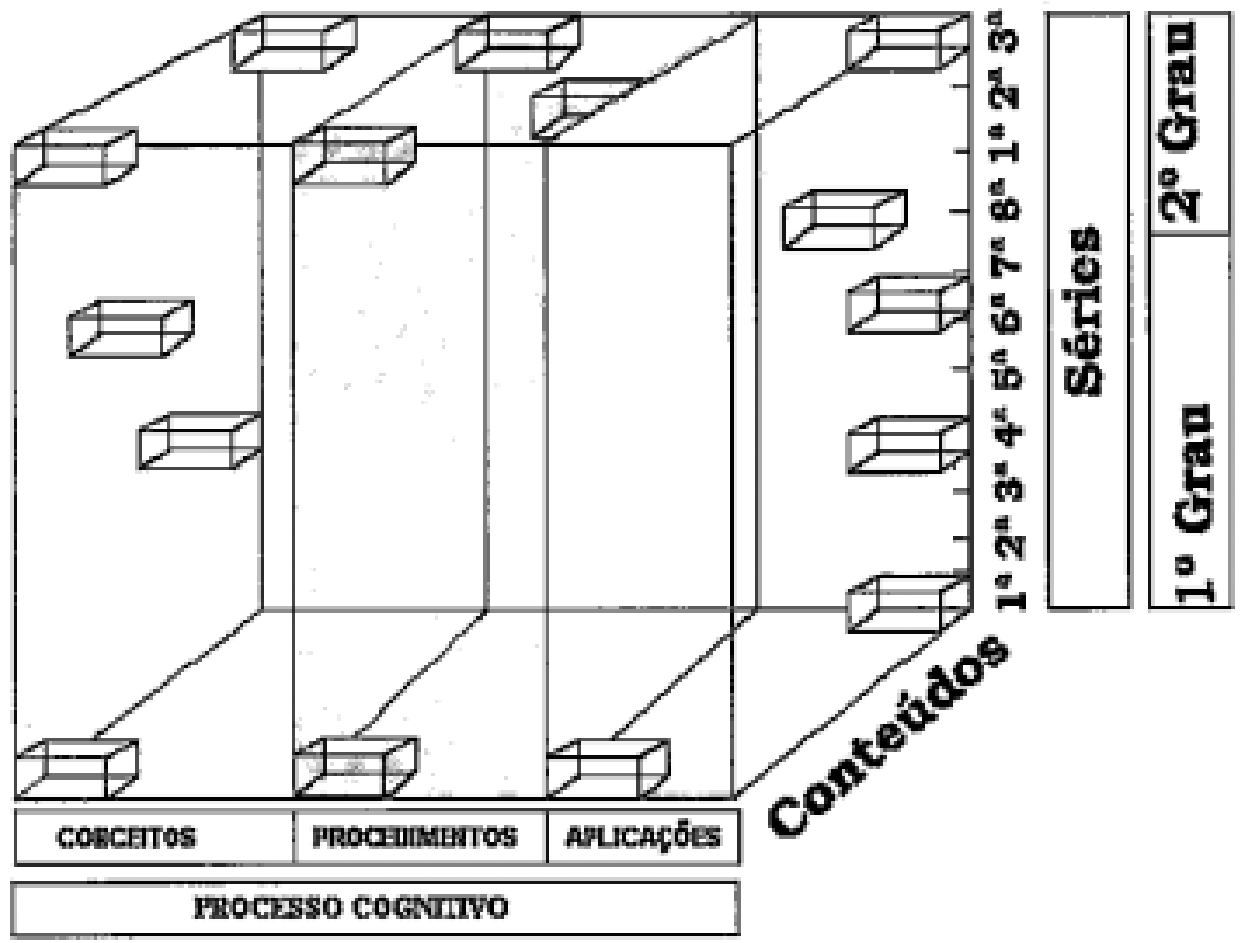

Construída a matriz, e antes de utilizá-la como suporte para a construçăo de itens, é preciso garantir a sua validade. Nesse sentido, é ela submetida a uma banca de especialistas que têm a incumbência de pronunciarem-se sobre a sua adequaçăo. Nesse momento, o que se pergunta é o seguinte: 1 . Será que a estrutura dos tópicos (e seu detalhamento) corresponde à ordenação lógica da disciplina? ; 2. Será que a matriz explora, à exaustăo, os objetivos curriculares propostos para a série $\mathbf{X}$ do grau Y? Trata-se de trabalho minucioso e árduo, mas que tem o condäo de expor eventuais fragilidades na matriz, ensejando alteraçöes importantes.

Completada mais essa etapa, uma equipe de professores experientes é convocada para a elaborar os itens. Algumas regras, de longa data testadas, servem de respaldo para que os itens saiam com qualidade. Por exemplo, dar preferência a textos não-redundantes e em linguagem natural, evitar ordem indireta, não misturar objetivos numa mesma questão, procurar manter o item independente dos demais etc. 
A construçăo de itens nåo é tarefa fácil. Os professores, mesmo os mais experientes, logo se däo conta de que, depois de terem construído alguns itens, começam a repetir-se, mudando pequenos detalhes, mas mantendo a mesma estrutura. Isso pode ser bom, por um lado, uma vez que contribui para o aumento do acervo de um particular tipo de item; por outro lado, ofuscados pela abundância de itens semelhantes, os professores podem perder a oportunidade de exploração de todas as caselas da matriz de especificações.

Finalmente, construídos os itens, o passo seguinte é submetê-los a uma outra banca de especialistas com o objetivo de assegurar que não haja descompasso entre o que propōe a matriz e o que cobram os itens. Essa fase busca dar legitimidade aos itens $\mathrm{e}$ impedir que sejam propostas questōes inadequadas a algum nível escolar.

\section{FINALIZANDO}

Esperamos ter conseguido demonstrar a importância de que se reveste a construção de bons itens com vistas numa avaliação que produza crescimento simultâneo de alumos e respectivos professores. A semelhança de uma estrada que une dois pontos, uma proposta curricular precisa, além dos pontos de saída e chegada, de fachos que iluminem a trajetória de todos os implicados no processo: os objetivos.

Os objetivos, por sua vez, devern merecer tratamento adequado, a fim de que especifiquem claramente os comportamentos de saída, observáveis, que possam denunciar a aquisição, pelo aluno, das dimensões cognitivas planejadas pelo educador. Nesse sentido, a matriz tridimensional de especificações cumpre o importante papel de "aprisionar", em unidades pequenas, objetivos reduzidos à sua forma mais simples, de modo que os itens construídos com o seu suporte possam ser especificos, não-redundantes e isentos de contaminaçôes de objetivos colateriais.

A moderna Teoria da Resposta ao Item, concebida nos anos 50 e só mais recentemente desenvolvida graças aos avanços da Estatística e da Informática, constitui campo fértil para a utilizaçăo de uma matriz tridimensional, como a apresentada, e presta-se, com algumas vantagens sobre as teorias clássicas, à produção de itens em larga escala, capazes de, a um so tempo, avaliar a "saúde" curricular de uma comunidade bem como a posição individual de alunos no seu grupo de referência. Vale a pena tentar! 
